\title{
Comparison of bromfenac $0.09 \%$ QD to nepafenac 0.1\% TID after cataract surgery: pilot evaluation of visual acuity, macular volume, and retinal thickness at a single site
}

This article was published in the following Dove Press journal:

Clinical Ophthalmology

29 June 2012

Number of times this article has been viewed

\author{
Melissa Cable \\ Discover Vision Centers, \\ Independence, MO, USA
}

Correspondence: Melissa Cable 474I S Cochise Dr, Independence, MO 64055, USA

Tel + I 8164781230

Fax + I 8164784413

Email mcable@discovervision.com
Purpose: The purpose of this study was to investigate the clinical outcomes of bromfenac ophthalmic solution $0.09 \%$ once daily (QD) and nepafenac $0.1 \%$ ophthalmic suspension three times daily following cataract extraction with posterior chamber intraocular lens implantation, specifically looking at any differences in Early Treatment Diabetic Retinopathy Study visual acuities, macular volume, and/or retinal thickness changes.

Methods: Subjects were randomly assigned to receive either bromfenac $(n=10)$ QD or nepafenac $(\mathrm{n}=10)$ three times daily. Dosing began 3 days before cataract surgery, continuing to day 21 postsurgery. In addition to the investigated nonsteroidal antiinflammatory drug regimen, all subjects received antiinfective intraoperative and postoperative standard of care. Subjects were followed at 1 day and 1, 3, and 6 weeks postoperatively. Study visit assessments included best-corrected visual acuity, biomicroscopy, summed ocular inflammation score (anterior chamber cells and flare grading), intraocular pressure measurement, adverse event recording, and concomitant medication review. Optical coherence tomography was performed at 1,3 , and 6 weeks.

Results: Both treatment groups had similar baseline measurements. Outcomes for mean letters $\operatorname{read}(P=0.318)$, mean change in macular volume $(P=0.665)$, and retinal thickness $(P=0.552)$ were not statistically different between the groups from baseline through week six, although independently only the bromfenac group demonstrated a statistically significant improvement in letters gained from baseline to week six $(P=0.040)$. In the same time period, mean macular volume and retinal thickening worsened in the nepafenac group, demonstrating a statistically significant increase $(P=0.006)$ at week six for macular volume when compared to baseline. One subject in the nepafenac group experienced recurrent inflammation at week six, was unmasked, and then rescued with bromfenac $0.09 \%$ QD and difluprednate $0.05 \%$ QD.

Conclusion: Both bromfenac and nepafenac resulted in positive clinical outcomes of Early Treatment Diabetic Retinopathy Study visual acuities. Postoperative measurements of macular volume and retinal thickness of bromfenac subjects showed a trend toward improved vision, less retinal thickening, and more stable macular volumes overall.

Keywords: NSAIDs, phacoemulsification, inflammation, cataract, macular volume, retinal thickness

\section{Introduction}

Cataract is a progressive disease, and is the leading cause of blindness worldwide, accounting for over half of Medicare costs associated with vision in the United States. ${ }^{1}$ Without appropriate surgical intervention, patients experience a steady decline in visual 
acuity, which may lead to reduced physical function. Cataract extraction ranks among the most commonly performed surgical interventions in the United States and markedly improves patients' visual functioning and quality of life. ${ }^{2-5}$ The preferred method of cataract removal is extracapsular extraction, most commonly by phacoemulsification followed by intraocular lens (IOL) implantation in the capsular bag..$^{3,4}$ Topical nonsteroidal antiinflammatory drugs (NSAIDs) have been established as the standard of care, used both preoperatively and postoperatively to treat inflammation and support full recovery of optimal visual acuity. ${ }^{6,7}$

Ocular surgery induces an inflammatory response leading to increased prostaglandin production. ${ }^{8}$ Surgical trauma activates phospholipase A2, which in turn liberates arachidonic acid from the cell membrane. Arachidonic acid can be acted upon by lipoxygenase, which converts arachidonic acid to leukotrienes, or it can be acted upon by cyclooxygenase (COX) and be converted to prostaglandins. There are two isoforms of COX in the cell, COX-1 and COX-2. COX-1 is a constitutive enzyme that facilitates functions such as platelet aggregation. COX-2, which is inducible, is upregulated in states of inflammation. COX-2 converts arachidonic acid into several prostaglandins; the most important of which is prostaglandin E2, which mediates the characteristic signs of inflammation. ${ }^{8}$ NSAIDs inhibit prostaglandin synthesis, thereby controlling the associated inflammation and pain. NSAIDs have been well recognized as an effective treatment in the management of postoperative ocular inflammation by acting as potent inhibitors. ${ }^{8-11}$ Inflammatory response, initiated by surgical intervention, can ignite a cascade of further inflammatory events leading to a breakdown of the blood-retinal barrier and accumulation of intraretinal fluid and macular thickening/edema. ${ }^{12,13}$ Previous studies have documented that $27 \%-41 \%$ of eyes undergoing phacoemulsification experience an increase in macular thickness. ${ }^{12,14}$ Postoperative thickening of the macula has been shown to correlate with visual acuity changes, resulting in transient or permanent impairment of vision. ${ }^{15-17}$

Two topical NSAIDs that are currently approved for the postoperative treatment of pain and inflammation in cataract extraction patients are bromfenac $0.09 \%$ ophthalmic solution (Bromday ${ }^{\mathrm{TM}}$; ISTA Pharmaceuticals Inc, Irvine, CA) and nepafenac $0.1 \%$ ophthalmic suspension $\left(\mathrm{Nevanac}^{\circledR}\right.$; Alcon Laboratories Inc, Fort Worth, TX). Both purport to treat ocular inflammation by acting as a potent inhibitor of both COX-1 and COX-2 enzyme isoforms. ${ }^{18,19}$ Nepafenac is converted in the ocular tissues to amfenac, which then inhibits COX enzymes..$^{20}$ Both have been the subject of clinical trials confirming their efficacy and safety in the treatment of pain and inflammation. ${ }^{21-24}$ Clinical studies to date lack clarity on which topical NSAID may be the most efficacious. ${ }^{25-27}$ This pilot study was designed to provide information on how clinical outcomes of a new dosing regimen of bromfenac $0.09 \%$, recently approved for once daily (QD) dosing, might compare to nepafenac $0.1 \%$, which is dosed three times daily (TID). ${ }^{22,28,29}$ The author knows of no prior studies looking at these medications in this dosing regimen in a head-to-head fashion. Primary efficacy endpoints for this study were bestcorrected visual acuity (BCVA) (Early Treatment Diabetic Retinopathy Study [ETDRS] letters), optical coherence tomography (OCT) measurements of macular volume and retinal thickness, and summed ocular inflammation scores (SOIS). Secondary efficacy endpoints included safety assessments such as adverse events, both serious and nonserious, and intraocular pressure measurements.

\section{Patients and methods}

The study was a prospective, randomized, investigatormasked, parallel-group, comparative clinical trial investigating two postcataract topical NSAIDs, bromfenac ophthalmic solution $0.09 \%$ QD and nepafenac ophthalmic suspension $0.1 \%$ TID. The investigator, ophthalmic technicians, and subjects were masked to the study drug identity for the entirety of the trial - during data collection and analysis unless it was determined that masking should be broken. In that event, it was determined that the date, time, and reason for unmasking were to be documented as soon as possible. This pilot study was conducted at a single United States surgical center by a single surgeon. The protocol was approved by Sterling Institutional Review Board (Atlanta, GA) on November 2, 2011 and conducted in accordance with the principles of the Declaration of Helsinki approved in 1964 and its amendments (World Medical Association, October 2008). Informed consent was obtained from all subjects electing to participate in the study. Participating subjects received study drug, study-related procedures, and study visits at no charge to either the subjects or to their insurance company. Subjects received a nominal fee for their participation.

Subjects undergoing unilateral cataract extraction by phacoemulsification with posterior chamber IOL implantation were eligible for participation in the study. Participating subjects agreed to participate in the study, were provided and signed an informed consent, and met the inclusion and exclusion criteria (Table 1). Patients with diabetes could be enrolled as long as ocular findings were not determined to be clinically significant. Patients could not be enrolled if they 
Table I Inclusion and exclusion criteria

Inclusion criteria
$\geq 18$ years of age
Scheduled for unilateral cataract surgery with posterior chamber
intraocular lens implantation and for whom no other ophthalmic
surgical procedures (eg, relaxing incisions, iridectomy, conjunctival
excisions) are to be conducted during the cataract surgery
BCVA of $20 / 200$ or better in either eye

IOP $\geq 5 \mathrm{mmHg}$ and $\leq 22 \mathrm{mmHg}$ (in study eye)

Agree not to have any other ocular surgical procedures in the study or fellow (nonstudy) eye within 15 days before the initiation of NSAID dosing or throughout the duration of the study

Able to self-administer topical ocular medication (or have a caregiver available to instill all doses) Women capable of becoming pregnant agree to have urine pregnancy testing performed at screening (must be negative) and use a medically acceptable form of birth control throughout the study duration and for at least I week before and after completion of the study Signed informed consent

\section{Exclusion criteria}

Known hypersensitivity to bromfenac or nepafenac or their components Known hypersensitivity to salicylates (ie, aspirin) or to other NSAIDs

Intraocular inflammation (ie, cells or flare in the anterior chamber as measured on slit lamp examination) in the study eye at the screening visit

Known blood dyscrasia or bone marrow suppression, a diagnosis of uncontrolled/unstable peptic ulcer disease, inflammatory bowel disease, or ulcerative colitis, or any uncontrolled/unstable pulmonary, cardiac, vascular, autoimmune, hepatic, renal, or central nervous system disease Used ocular, topical, or systemic NSAIDs, or ocular, topical, or systemic gentamicin, or cyclosporine ophthalmic emulsion within 7 days before initiation of dosing with study NSAID or throughout the duration of the study Used any ocular prostaglandins within 30 days before initiation of dosing with study NSAID or throughout the duration of the study Superficial punctate keratitis

Active corneal pathology noted in the study eye at the screening visit. Active corneal pathology is defined as corneal pathology that is nonstable, or greater than mild, or will compromise assessment of the safety or efficacy of treatment Any extraocular/intraocular inflammation in the study eye noted at the screening visit (blepharitis allowed if mild only, and no concurrent conjunctivitis or lid erythema/edema) or ongoing, unresolved uveitis Used topical, ocular, inhaled, or systemic steroids within 14 days before screening

Radial keratotomy, corneal transplant, or corneal refractive surgery in the study eye within the last 2 years

History of abuse of alcohol/drugs within 6 months before the screening visit

Pregnant or nursing/lactating

Participated in any other study of an investigational drug or device within 30 days before randomization

Abbreviations: BCVA, best-corrected visual acuity; IOP, intraocular pressure; NSAID, nonsteroidal antiinflammatory drug.

had preexisting macular or retinal edema or more than two microaneurysms within the fundus.

Twenty subjects were enrolled in the study and assigned sequentially, according to a computer-generated randomization list, in a ratio of 1:1 to receive either bromfenac ophthalmic solution $0.09 \%$ or nepafenac ophthalmic suspension $0.1 \%$. The study coordinator reviewed inclusion/exclusion criteria with subjects, received the computer-generated list, and dispensed study medication. The investigator and technicians recording study data were masked to treatment group assignment for the duration of the trial and during data collection unless a subject was unmasked. Screening evaluations were conducted within 8 days before the date planned for cataract extraction and included an assessment of medical history and recording of demographic information, complete bilateral ophthalmic examination (BCVA, OCT, biomicroscopic examination, intraocular pressure measurement, and dilated funduscopic examination), and urine pregnancy test for female participants.

\section{Treatment}

Randomized subjects were instructed to initiate dosing with their assigned topical formulation, either bromfenac ophthalmic solution $0.09 \%$ QD or nepafenac ophthalmic suspension $0.1 \%$ TID, 3 days before surgery as well as on the day of surgery. Subjects received study medication in the original Food and Drug Administration-approved packaging. Uncomplicated phacoemulsification was performed by 
one surgeon for all study subjects with IOL implantations (Tecnis ${ }^{\circledR}$ 9000series; Abbott Medical Optics Inc, Santa Ana, CA). Usual cataract procedure was followed for all subjects, including administration of preoperative antiinfective moxifloxacin $0.5 \%$ TID and study NSAID according to treatment guidelines beginning 3 days prior to surgery. Intraoperatively, subjects received timolol $0.5 \%$, prednisolone acetate $1 \%$, gatifloxacin ophthalmic, and intracameral moxifloxacin, and postoperative moxifloxacin $0.5 \%$ was given TID for 1 week with difluprednate QD for 3 weeks. As required by exclusion criteria, subjects received no ocular NSAIDs or steroids for 2 weeks before, during, or after surgery other than the investigational study medication (bromfenac ophthalmic solution $0.09 \%$ QD or nepafenac ophthalmic suspension $0.1 \%$ TID). Cumulative dissipated energy from an INFINITI ${ }^{\circledR}$ Vision System (Alcon) was recorded to report the amount of energy dissipated in the eye during cataract surgery.

Subjects attended follow-up assessments the day after surgery and then at 1, 3, and 6 weeks after surgery. Assessments performed at each study visit included BCVA evaluation (ETDRS letters), biomicroscopic examination, SOIS cell and flare grading, intraocular pressure measurement, adverse event recording, and a review of concomitant medications. OCT was performed at the office visits of weeks one, three, and six. All measurements were completed by masked observers.

\section{Assessments}

All subjects had medical histories, ongoing medications, underlying medical conditions, and demographic data (including date of birth, gender, iris color, and ethnicity) recorded at the screening visit. BCVA was measured at the screening visit; all subsequent visits employed the ETDRS chart and acuities were recorded using the logarithm of the minimum angle of resolution system. A bilateral slit lamp biomicroscopy (without pupil dilation) was performed at each study visit to assess for extraocular or intraocular inflammation in the study eye or fellow eye. Dilated funduscopic exams were performed at the initial screening visit and again at the fifth study visit (at $42 \pm 3$ days).

An experienced ophthalmic technician obtained all Stratus $\mathrm{OCT}^{\mathrm{TM}}$ (Carl Zeiss Meditec Inc, Dublin, CA) scans for all study subjects. OCT captures the interference pattern between backscattered light and a reference beam to display threedimensional images which provide morphometric and quantitative information about various ocular structures, including the retina. Two scan patterns were used; the first was the fast macular thickness protocol, using six radial line scans through a common central axis (fovea) with a retinal thickness/volume tabular output and a retinal-thickness output report. Central retina thickness was defined as the distance between the inner limiting membrane of the retina and the inner border of the choriocapillaris measured in the central 1-mm area of the (minimum) 7-mm posterior pole scan. The Stratus software,Version 5.0, (Carl Zeiss, Meditec, Dublin, CA) also calculated the total macular volume within the 7-mm-diameter scanned area, representing a weighted average of the central, inner, and outer subfields multiplied by the area of the grid. Macular volume is an objective indicator of macular swelling, and can illustrate the amount of inflammation following cataract surgery. All OCT scans were reviewed by the study principal investigator for quality of foveal centration and signal strength.

Ocular inflammation was determined using SOIS to quantify cells or flare. Anterior chamber cells were assessed using a slit lamp biomicroscope at $16 \times$ magnification with a $0.3 \times 1-\mathrm{mm}$ oblique high-intensity beam. Cell counts were measured twice and converted to a grade (Table 2), in which the mean score was then calculated. Anterior chamber flare was assessed once and graded using the scale also included in Table 2. The SOIS was then calculated as the sum of the cell and flare grades.

\section{Statistical analysis}

This study was planned as a pilot study to determine the clinical outcomes for a small group $(\mathrm{N}=20)$ of study participants and was therefore not powered to illustrate statistical superiority for either group. Because of the small number of study participants, separate analyses regarding gender and race were not attempted.

The primary efficacy endpoints for this study were BCVA, SOIS, and OCT measurements of retinal thickness and volume. Data was collected and entered by the primary investigator who remained masked to the study drug. Data analysis was performed by a statistician and a $P$ value

Table 2 Ocular inflammation grading scale

\begin{tabular}{lllll}
\hline \multicolumn{2}{l}{ Anterior chamber cells } & & \multicolumn{2}{l}{ Anterior chamber flare } \\
\cline { 1 - 2 } Grade & Cell count & & Grade & Flare count \\
\hline 0 & 0 & 0 & Complete absence \\
0.5 & I-5 cells (trace) & & - & - \\
\hline & $6-15$ & $\mathrm{I}$ & Very slight (barely detectable) \\
2 & $16-25$ & 2 & Moderate (iris and lens clear) \\
3 & $26-50$ & 3 & Marked (iris and lens hazy) \\
4 & $>50$ & 4 & Intense (fibrin clot) \\
\hline
\end{tabular}

Notes: Anterior chamber mean cell counts were calculated from two measurements and converted to a grade. Anterior chamber flare was assessed once and the summed ocular inflammation score was then calculated as the sum of the cells and flare grades. 
of $<0.05$ was considered statistically significant. All analyses of efficacy were to be conducted on the intent-to-treat population, defined as all randomized subjects, where subjects were analyzed in the group to which they were randomized. Two analyses of efficacy were performed: an analysis of data based on last observation carried forward and an analysis of data based on observed cases. Paired $t$-tests were used for within-subject baseline comparison of results.

\section{Results}

\section{Study population}

A total of 20 recruited subjects (ten women and ten men; mean age 69.9 years [range $46-84$ years]) met the inclusion criteria and were randomly assigned to receive either bromfenac ophthalmic solution $0.09 \%$ QD $(n=10)$ or nepafenac ophthalmic suspension 0.1\% TID $(\mathrm{n}=10)$. Baseline demographic and clinical characteristics are summarized in Table 3 . The majority of subjects $(85 \%)$ were Caucasian and baseline characteristics of treatment groups were comparable. Mean cumulative dissipated energy measurements for each group were similar, 5.853 seconds in the nepafenac group and 5.452 seconds in the bromfenac group.

One eye of each of the 20 subjects was enrolled in the study. All study subjects underwent uncomplicated phacoemulsification and IOL implantation and attended all follow-up visits. Subjects completed their assigned treatment regimen, with the exception of one subject in the nepafenac group. This subject was noted at the final postoperative visit to have complaints of worsened vision ( 0.10 logarithm of the minimum angle of resolution units), increasing SOIS, and ocular pain compared to the measurements at week three, and was unmasked and treated with topical difluprednate

Table 3 Summary of baseline demographics and clinical characteristics

\begin{tabular}{|c|c|c|}
\hline Variable & $\begin{array}{l}\text { Bromfenac } 0.09 \% \\
(n=10)\end{array}$ & $\begin{array}{l}\text { Nepafenac } 0.1 \% \\
(n=10)\end{array}$ \\
\hline \multicolumn{3}{|l|}{ Age (years) } \\
\hline Mean & 70.1 & 69.7 \\
\hline Range & $46-84$ & $54-84$ \\
\hline \multicolumn{3}{|l|}{ Gender } \\
\hline Male & 6 & 4 \\
\hline Female & 4 & 6 \\
\hline \multicolumn{3}{|l|}{ Race } \\
\hline Caucasian & 10 & 7 \\
\hline African American & & 2 \\
\hline American Indian & & 1 \\
\hline \multicolumn{3}{|l|}{ Study eye } \\
\hline Right & 5 & 6 \\
\hline Left & 5 & 4 \\
\hline
\end{tabular}

0.05\% QD and bromfenac 0.09\% QD for 2 weeks. At the 8-week postoperative period, visual acuity had improved to 0.0 logarithm of the minimum angle of resolution units, SOIS was zero, the subject reported no ocular pain, and all medications were discontinued.

\section{Efficacy}

Comparison of BCVA from baseline to week six for both groups is shown in Table 4. Mean baseline BCVA was similar for both groups: 43.3 ETDRS letters for the bromfenac group compared to 46.6 ETDRS letters for the nepafenac group. Over the study period, $90 \%$ of subjects in the bromfenac group experienced stable or improved visual acuity, as compared to $80 \%$ in the nepafenac group. At week one there was no statistically significant visual acuity improvement from baseline for either treatment or significant difference between the two treatment groups. Of particular note is the mean gain from baseline of 5.8 ETDRS letters at week six in the bromfenac group, which was a statistically significant improvement $(P=0.040)$ from baseline, in contrast to the mean gain from baseline of 1.7 ETDRS letters in the nepafenac group over the same time period.

All preoperative OCT scans were within normal limits and measurements of retinal thickness and macular volume were comparable between the two groups. Minimal increases in macular volume across the postoperative period were noted for each group. At week one there appeared to be thickening in the area of interest in the nepafenac group, whereas the bromfenac group appeared to remain stable; however, these findings were not statistically significant. Macular volumes at week three and week six increased slightly within the nepafenac group while the bromfenac group had a slight increase at week three but no change at all between week three and week six. The independent increase in macular volume from baseline to week six was statistically significant within the group treated with nepafenac $(P=0.006)$ but not in the bromfenac group (Figure 1).

Table 4 Comparison of best-corrected visual acuity using Early Treatment Diabetic Retinopathy Study letters read from baseline to week six for both treatment groups

\begin{tabular}{lll}
\hline Time & $\begin{array}{l}\text { Bromfenac 0.09\% } \\
(\mathbf{n}=\mathbf{~ 1 0 )}\end{array}$ & $\begin{array}{l}\text { Nepafenac 0.1\% } \\
(\mathbf{n}=\mathbf{~ 1 0 )}\end{array}$ \\
\hline $\begin{array}{l}\text { Preoperative (baseline) } \\
\text { Postoperative }\end{array}$ & 43.3 & 46.6 \\
I week & 51.3 & 52 \\
3 weeks & 50 & 49 \\
6 weeks & 49.1 & 48.3 \\
\hline
\end{tabular}




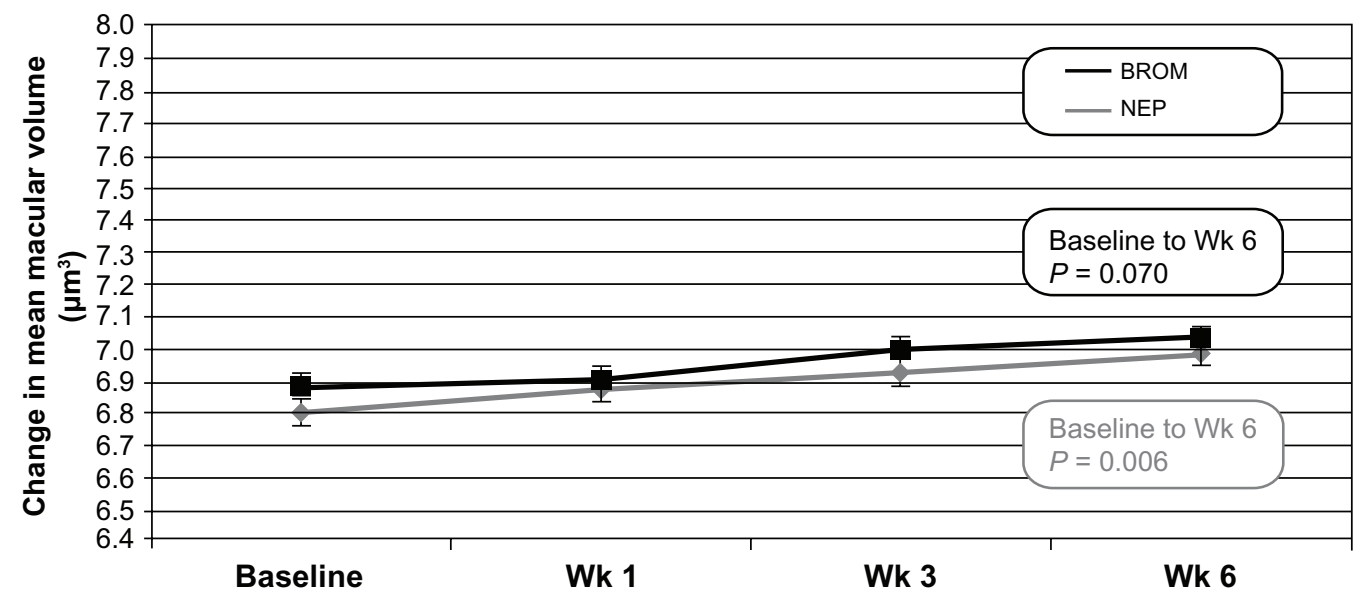

Figure I Change in mean macular volume.

Note: Error bars represent standard error.

Abbreviations: BROM, bromfenac; NEP, nepafenac; Wk, week.

The mean macular volumes for both groups at week one were very similar: $6.87 \mathrm{~mm}^{3}$ in the nepafenac group and $6.92 \mathrm{~mm}^{3}$ in the bromfenac group, which paralleled the changes in central retinal thickness at the same time point. At one week following surgery, the bromfenac group experienced a mean increase in retinal thickness of $5.5 \mu \mathrm{m}$ (baseline $225.7 \mu \mathrm{m}$ ) as compared to $0.6 \mu \mathrm{m}$ (baseline $211.9 \mu \mathrm{m}$ ) in the nepafenac group (not statistically different); however, by week three the mean change in retinal thickness from baseline was slightly lower in the bromfenac group $(5.1 \mu \mathrm{m})$ and substantially higher in the nepafenac group $(12.5 \mu \mathrm{m})$. Keeping in mind that treatment was stopped at week three, these changes remained consistent through to week six (Figure 2).

The anterior chamber cell count, SOIS grading, and flare were similar for both treatment groups at all study visits (Figure 3).

\section{Discussion}

This was a prospective, randomized study to evaluate the clinical characteristics of two commonly used NSAIDs in the treatment of inflammation and pain following cataract extraction surgery by phacoemulsification. The antiinflammatory effects of bromfenac $0.09 \%$ and nepafenac $0.1 \%$ are well documented, and the use of NSAIDs during the first 2 weeks following phacoemulsification has been shown to improve BCVA; however, comparative study of the clinical characteristics, including postoperative BCVA, macular volumes, and thickness, is somewhat limited. ${ }^{30}$ The effect of NSAIDs on macular thickness is a significant clinical concern as macular thickening may impact visual acuity outcomes. ${ }^{15,17}$ Preoperative and postoperative OCT studies revealed that $27 \%-41 \%$ of eyes undergoing uncomplicated phacoemulsification can experience increased macular

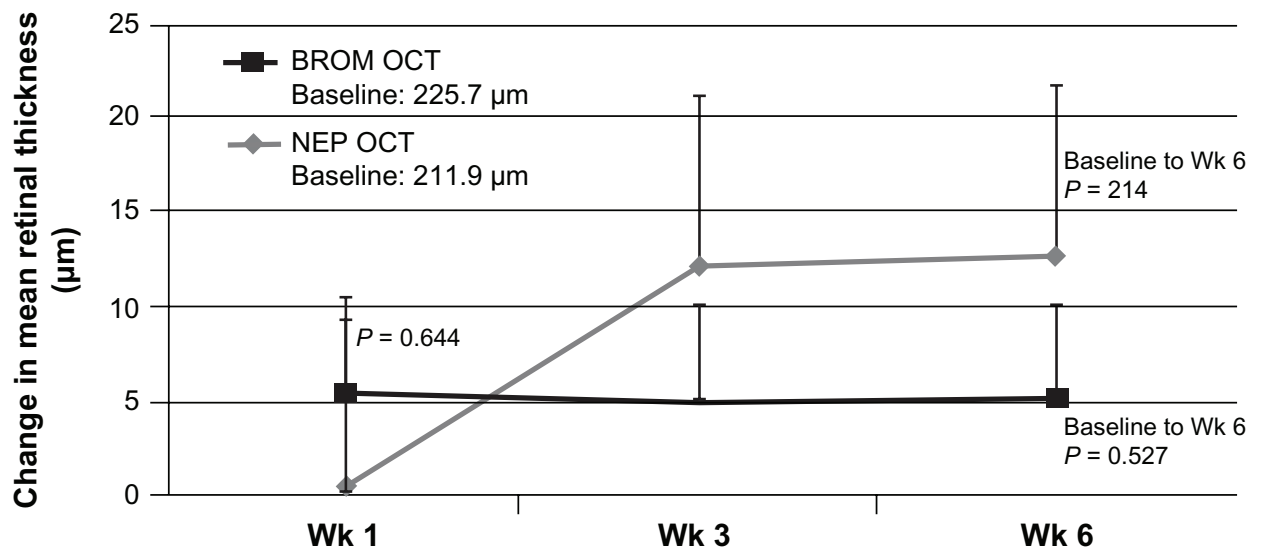

Figure 2 Change in mean retinal thickness.

Note: Error bars are the lowest standard error for all time points.

Abbreviations: BROM, bromfenac; NEP, nepafenac; OCT, optical coherence tomography; Wk, week. 


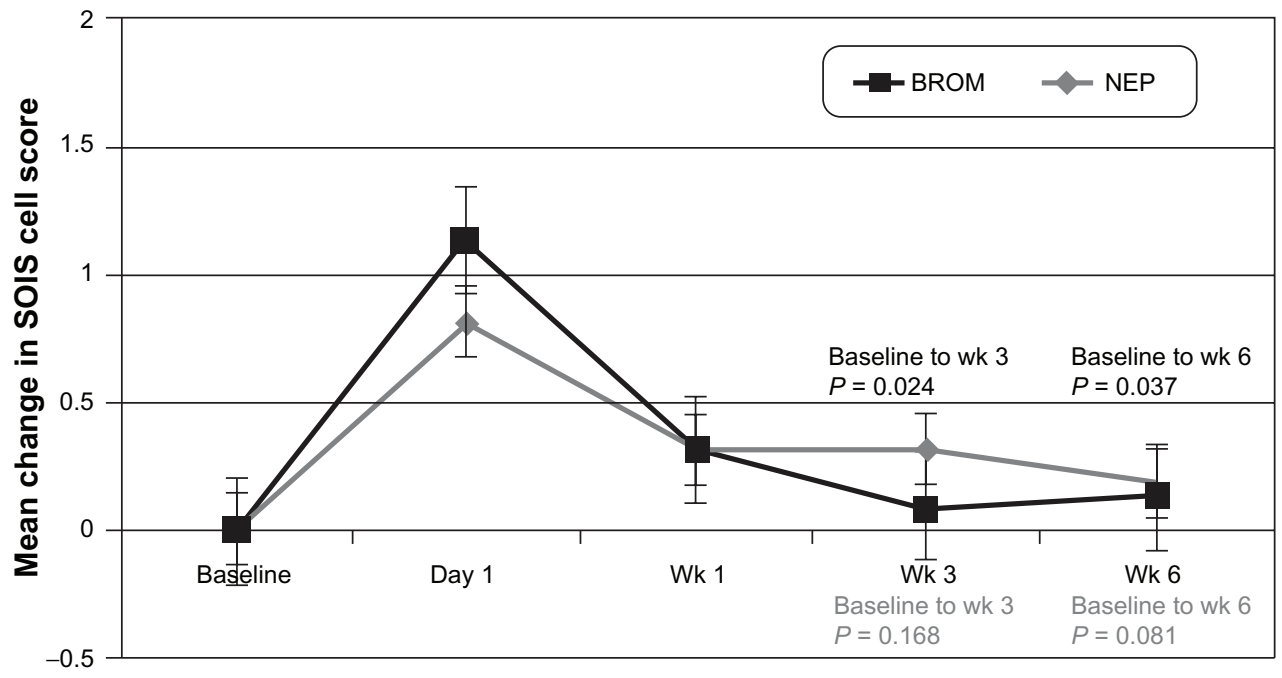

Figure 3 Change in mean summed ocular inflammation score cell score.

Note: Error bars represent standard error.

Abbreviations: BROM, bromfenac; NEP, nepafenac; SOIS, summed ocular inflammation score; Wk, week.

thickness peaking 4-6 weeks after surgery. ${ }^{12,14,31,32}$ Flach has documented that macular thickening can correlate with vision loss. ${ }^{17}$ Wittpenn et al reported that the addition of an NSAID to a postoperative regimen significantly reduced the incidence of macular thickening. ${ }^{15}$ They also found that there was a relationship, although not statistically significant, between postoperative retinal thickening of $>10 \mu \mathrm{m}$ and contrast sensitivity. ${ }^{15}$ In the present study population there were no statistically significant differences in ETDRS vision between the groups, although there was an increase in retinal thickness of $11.9 \mu \mathrm{m}$ from week one to week three in the nepafenac group and a decrease of $0.4 \mu \mathrm{m}$ in the bromfenac group in the same time period. A trend toward larger increases in mean macular volume in the nepafenac group compared to the bromfenac group was also noted. Contrast sensitivity was not tested as part of the study protocol. Vision recovery and improvement is the common and clinically important factor to all patients having routine cataract surgery and IOL implantation. Within the groups, subjects in the bromfenac group experienced a statistically significant improvement in BCVA as measured by ETDRS from baseline to week six, whereas those in the nepafenac group did not. This nonsignificant result of the BCVA mean improvement in the nepafenac group may have been influenced by the decline in BCVA of the single patient in this group who experienced recurrent inflammation at week six, who was unmasked and then rescued. A study of a larger cohort would be necessary to further explore this result.

In the present study population, the increase in macular volume from baseline to week six was statistically significant in the nepafenac group $(P=0.006)$ but not in the bromfenac group. This finding suggests that subjects in the nepafenac group were unable to maintain the same consistency of macular volume from baseline as subjects in the bromfenac group. Both groups showed a persistence of effect through the 6-week interval after medication dosing had concluded; however, the change in macular volume was not significantly different between the two treatment groups. Further study is warranted to examine this persistence of effect beyond the cessation of dosing.

A major limitation of this study is the small number of subjects, such that direct correlations of the study variable could not be evaluated; however, the results demonstrate findings in the clinical characteristics and outcomes for this subject group that should be considered for further study of a larger population.

\section{Conclusion}

In this study of subjects receiving NSAID treatment following phacoemulsification and IOL implantation, both bromfenac $0.09 \%$ ophthalmic solution dosed QD and nepafenac $0.1 \%$ ophthalmic suspension dosed TID are well tolerated and resulted in positive clinical outcomes. Results indicate that bromfenac subjects exhibit less retinal thickening overall, greater improvement in BCVA letters read from baseline, and less change in macular volume over the study period. Further testing, including power analyses to address the optimal number of subjects in each study arm, could be helpful in further understanding of efficacy differences between these two ophthalmic NSAIDs. 


\section{Disclosure}

This study was supported by a grant from ISTA Pharmaceuticals Inc (Irvine, CA). Dr Cable has participated in clinical trials sponsored by ISTA and is an appointed clinical expert. Results of this manuscript have been previously reported at the American Society of Retinal Specialists annual meeting in Boston, MA, August 2011.

\section{References}

1. Congdon N, Vingerling JR, Klein BE, et al. Prevalence of cataract and pseudophakia/aphakia among adults in the United States. Arch Ophthalmol. 2004;122(4):487-494.

2. Desai P, Minassian DC, Reidy A. National cataract surgery survey 1997-1998: a report of the results of the clinical outcomes. $\mathrm{Br} \mathrm{J}$ Ophthalmol. 1999;83(12):1336-1340.

3. Mangione CM, Phillips RS, Lawrence MG, Seddon JM, Orav EJ, Goldman L. Improved visual function and attenuation of declines in health-related quality of life after cataract extraction. Arch Ophthalmol. 1994;112(11):1419-1425.

4. McGwin G Jr, Scilley K, Brown J, Owsley C. Impact of cataract surgery on self-reported visual difficulties: comparison with a no-surgery reference group. J Cataract Refract Surg. 2003;29(5):941-948.

5. Schein OD, Steinberg EP, Javitt JC, et al. Variation in cataract surgery practice and clinical outcomes. Ophthalmology. 1994;101(6): $1142-1152$.

6. O'Brien TP. Emerging guidelines for use of NSAID therapy to optimize cataract surgery patient care. Curr Med Res Opin. 2005;21(7): 1131-1137.

7. Wolf EJ, Braunstein A, Shih C, Braunstein RE. Incidence of visually significant pseudophakic macular edema after uneventful phacoemulsification in patients treated with nepafenac. J Cataract Refract Surg. 2007;33(9):1546-1549.

8. Kim SJ, Flach AJ, Jampol LM. Nonsteroidal anti-inflammatory drugs in ophthalmology. Surv Ophthalmol. 2010;55(2):108-133.

9. Flach AJ. Topical nonsteroidal antiinflammatory drugs in ophthalmology. Int Ophthalmol Clin. 2002;42(1):1-11.

10. Samiy N, Foster CS. The role of nonsteroidal antiinflammatory drugs in ocular inflammation. Int Ophthalmol Clin. 1996;36(1): 195-206.

11. Schalnus R. Topical nonsteroidal anti-inflammatory therapy in ophthalmology. Ophthalmologica. 2003;217(2):89-98.

12. Lobo CL, Faria PM, Soares MA, Bernardes RC, Cunha-Vaz JG. Macular alterations after small-incision cataract surgery. $J$ Cataract Refract Surg. 2004;30(4):752-760.

13. McColgin AZ, Heier JS. Control of intraocular inflammation associated with cataract surgery. Curr Opin Ophthalmol. 2000;11(1):3-6.

14. Sourdille P, Santiago PY. Optical coherence tomography of macular thickness after cataract surgery. $J$ Cataract Refract Surg. 1999;25(2):256-261.

15. Wittpenn JR, Silverstein S, Heier J, et al. A randomized, masked comparison of topical ketorolac $0.4 \%$ plus steroid vs steroid alone in low-risk cataract surgery patients. Am J Ophthalmol. 2008;146(4): $554-560$.

Clinical Ophthalmology

\section{Publish your work in this journal}

Clinical Ophthalmology is an international, peer-reviewed journal covering all subspecialties within ophthalmology. Key topics include: Optometry; Visual science; Pharmacology and drug therapy in eye diseases; Basic Sciences; Primary and Secondary eye care; Patient Safety and Quality of Care Improvements. This journal is indexed on Submit your manuscript here: http://www.dovepress.com/clinical-ophthalmology-journal
16. Blumenkranz MS, Haller JA, Kuppermann BD. Correlation of visual acuity and macular thickness measured by optical coherence tomography in patients with persistent macular edema. Retina. 2010;30(7):1090-1094.

17. Flach AJ. The incidence, pathogenesis and treatment of cystoid macular edema following cataract surgery. Trans Am Ophthalmol Soc. 1998;96:557-634.

18. Kida T, Ogawa T, McNamara TR, Song CK, Gow JA. Evaluations of the human COX-2 inhibition for amfenac, bromfenac, diclofenac, and ketorolac. Paper presented at: American Society of Cataract and Refractive Surgery Symposium on Cataract, IOL, and Refractive Surgery; April 27-May 2, 2007; San Diego, CA.

19. Gamache DA, Graff G, Brady MT, Spellman JM, Yanni JM. Nepafenac, a unique nonsteroidal prodrug with potential utility in the treatment of trauma-induced ocular inflammation: I. Assessment of antiinflammatory efficacy. Inflammation. 2000;24(4):357-370.

20. Bucci FA Jr, Waterbury LD. Prostaglandin E2 inhibition of ketorolac $0.45 \%$, bromfenac $0.09 \%$, and nepafenac $0.1 \%$ in patients undergoing phacoemulsification. Adv Ther. 2011;28(12):1089-1095.

21. Donnenfeld ED, Holland EJ, Stewart RH, et al. Bromfenac ophthalmic solution $0.09 \%$ (Xibrom) for postoperative ocular pain and inflammation. Ophthalmology. 2007;114(9):1653-1662.

22. Silverstein SM, Cable MG, Sadri E, et al. Once daily dosing of bromfenac ophthalmic solution $0.09 \%$ for postoperative ocular inflammation and pain. Curr Med Res Opin. 2011;27(9):1693-1703.

23. Nardi M, Lobo C, Bereczki A, et al. Analgesic and anti-inflammatory effectiveness of nepafenac $0.1 \%$ for cataract surgery. Clin Ophthalmol. 2007;1(4):527-533.

24. Lane SS, Modi SS, Lehmann RP, Holland EJ. Nepafenac ophthalmic suspension $0.1 \%$ for the prevention and treatment of ocular inflammation associated with cataract surgery. J Cataract Refract Surg. 2007;33(1):53-58.

25. Walters T, Raizman M, Ernest P, Gayton J, Lehmann R. In vivo pharmacokinetics and in vitro pharmacodynamics of nepafenac, amfenac, ketorolac, and bromfenac. J Cataract Refract Surg. 2007;33(9):1539-1545.

26. Bucci F Jr, Waterbury LD. Comparison of ketorolac $0.4 \%$ and bromfenac $0.09 \%$ at trough dosing: aqueous drug absorption and prostaglandin E2 levels. J Cataract Refract Surg. 2008;34(9):1509-1512.

27. Kawaguchi T, Kida T, Nemoto S, et al. Effect of bromfenac ophthalmic solution on ocular inflammation and corneal epithelial barrier function following cataract surgery. Nihon Ganka Kiyo. 2003;54(4):276-279. Japanese.

28. Bromday ${ }^{\mathrm{TM}}$ (bromfenac ophthalmic solution) $0.09 \%$ [package insert]. Irvine, CA: ISTA Pharmaceuticals Inc; 2011.

29. $\operatorname{Nevanac}^{\circledR}$ (nepafenac ophthalmic suspension) $0.1 \%$ [package insert]. Fort Worth, TX: Alcon Laboratories Inc; 2011.

30. Miyake K, Masuda K, Shirato S, et al. Comparison of diclofenac and fluorometholone in preventing cystoid macular edema after small incision cataract surgery: a multicentered prospective trial. Jpn $J$ Ophthalmol. 2000;44(1):58-67.

31. Perente I, Utine CA, Ozturker C, et al. Evaluation of macular changes after uncomplicated phacoemulsification surgery by optical coherence tomography. Curr Eye Res. 2007;32(3):241-247.

32. Biro Z, Balla Z, Kovacs B. Change of foveal and perifoveal thickness measured by OCT after phacoemulsification and IOL implantation. Eye (Lond). 2008;22(1):8-12.

\section{Dovepress}

PubMed Central and CAS, and is the official journal of The Society of Clinical Ophthalmology (SCO). The manuscript management system is completely online and includes a very quick and fair peer-review system, which is all easy to use. Visit http://www.dovepress.com/ testimonials.php to read real quotes from published authors. 